\title{
BRONCHIAL ADENOMA IN CHILDHOOD
}

\author{
BY \\ K. D. ROBERTS \\ From the Children's Hospital, Birmingham
}

(RECEIVED FOR PUblCATION MARCH 22, 1954)

Bronchial adenoma is not a common condition under the age of 20 years and is exceedingly rare in childhood. The following is the youngest patient to be reported in this country.

\section{Case Report}

D.F., a 6-year-old girl, came to the Children's Hospital, Birmingham, in February, 1953, because of seven attacks of 'left basal pneumonia', the last being in July, 1952 . The first illness had been treated in Malaya in 1951 and had responded to a course of streptomycin and sulphonamides.

She was a well built, somewhat pallid child with no symptoms. Finger clubbing was absent; the trachea was central and the apex beat in the fifth intercostal space in the mid-clavicular line. There was an area of impaired percussion note and diminished air entry at the left base. The Mantoux test $(1$ in 1,000) was negative.

Radiography showed a partial collapse of the left lower lobe with honeycomb air shadows in this area; on bronchographic examination the basal segments of the left lower lobe could not be filled and the lower lobe bronchus, just below the apical branch, had a pointed termination suggestive of intra-bronchial obstruction; the apical segment of the lower lobe was large and appeared healthy (Fig. 1).

Sputum culture produced a growth of penicillinsensitive Streptococcus viridans, pneumococci and Staphylococcus aureus. The pre-operative diagnosis was bronchiectasis with segmental collapse due to bronchial occlusion and it was decided to perform resection of the basal segments of the left lower lobe, with conservation of the apical segment.

Operation on March 11 was performed under thiopentone, tubo-curarine and endotracheal nitrous oxide and oxygen anaesthesia.

With the child in the lateral position, the left chest was opened through the bed of the resected sixth rib. Adhesions between the partially collapsed basal segments of the lower lobe, the diaphragm and the chest wall were divided. The fissure was dissected and the artery and vein to the basal segments were divided and ligated. The bronchus was cleared and clamped low down; it was then opened and a smooth firm, yellowish nodule, the size of a pea, was seen occluding the lumen. The tumour was attached by a broad pedicle and was removed together with the portion of bronchus to which it was attached. The bronchial stump was trimmed to the level of the apical segmental bronchus, closed with interrupted No. 80 thread sutures and covered with pleura. Apical and basal intercostal tube drains were inserted and the chest closed.

The post-operative course was uneventful; the remainder of the left lung remained well expanded and the child was discharged two weeks after operation.

The child has remained well since operation. Radiographic examination 10 months' later showed that the apical segment of the lower lobe was well expanded and bronchoscopy excluded recurrence.

\section{Histological Report}

In the basal segments of the left lung there are a great number of spaces, $1 \mathrm{~mm} .-1 \mathrm{~cm}$. in diameter, lined by ciliated, columnar epithelium, showing plain muscle fibres, cartilage and mucous glands in the walls, and filled with homogeneous eosinophilic material containing

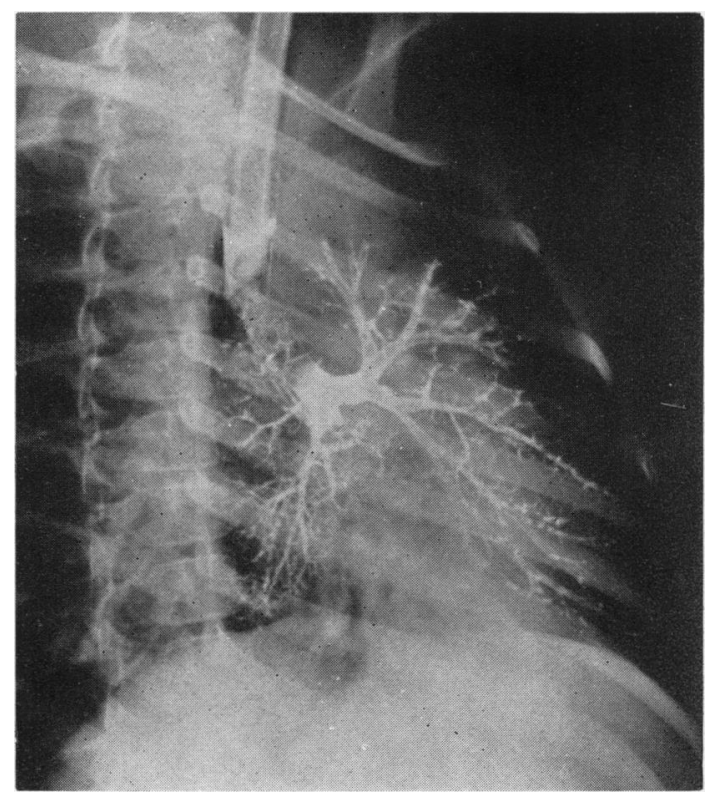

Fig. 1.-Bronchogram showing obstruction of the left lower lobe bronchus below the apical segment of the bronchus. 
desquamated epithelial cells. There are no inflammatory changes in the walls; the intervening pulmonary parenchyma shows atelectasis, oedema and desquamative catarrh (Fig. 2).

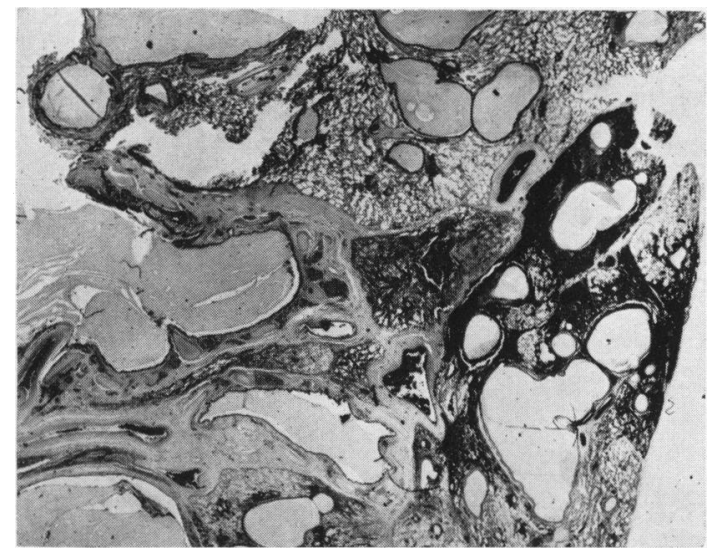

Fig. 2.-Low-power photomicrograph of a section cut from the basal segments of the left lower lobe showing cystic spaces.

The intrabronchial nodule is covered with regular, normal, ciliated columnar epithelium. It consists of nests and strands of round and polyhedric cells separated by narrow strands of connective tissue. The nests are either solid or show vesicles with either colourless, granular material or frequently with calcified secretion. The cells in the solid areas are about $30 \mu$ in diameter; they have a vesicular nucleus with one nucleolus and an abundant, foamy cytoplasm. There is some irregularity in nuclear shapes and a few possibly atypical mitoses (Fig. 3).

\section{Review of the Literature}

Jesberg (1926) reported a bronchial polypoid tumour in a boy of 6 years with 'wheezing' in the chest; the symptoms were relieved by bronchoscopic removal of the tumour, but the exact diagnosis is in doubt owing to lack of histological confirmation.

Rosenblum and Klein (1935) treated an 11-year-old boy with an adenoma of the right main bronchus; this had caused recurrent haemoptysis, cough, fever and wasting, with atelectasis of the right lower lobe. Symptomatic improvement followed bronchoscopic removal and the atelectatic lobe re-expanded, but subsequent bronchography revealed tubular bronchiectasis.

Kramer and Som (1935), reviewing 23 patients in their practice, noted that the youngest was 13 years old but no details were given.
Berger, Boreadis and Kremens (1953) treated a boy of 4 years suffering from collapse of the left lower lobe; at bronchoscopy a polypoid mass was seen in the distal part of the left main bronchus. Endoscopic removal was followed by bronchostenosis and, subsequently, pneumonectomy was performed; at operation peribronchial extension of the tumour was found to have occurred.

Price Thomas (1954) excised a bronchial adenoma and part of the right upper lobe bronchus, re-constructing the bronchial wall, in a girl of 11 years, who had had an attack of pulmonary infection followed by partial atelectasis.

\section{Discussion}

Symptoms of bronchial adenoma may be due to the tumour itself (cough, haemoptysis) or to the effects of bronchial obstruction. Foster-Carter (1941), reviewing 47 cases from the literature with 22 patients from the Brompton Hospital, showed that bronchial occlusion may cause dyspnoea, perhaps with paroxysmal asthmatoid attacks, and, in $60 \%$ of cases, is associated with infection (bronchiectasis, lung abscess or empyema).

Recurrent haemoptysis is usually accepted as the commonest symptom; it was absent in this patient and occurred in only $50 \%$ of Price Thomas's series (1954).

The radiological appearance is that of an opacity if the tumour is large, and a collapsed segment or lobe may be seen. Partial bronchial obstruction

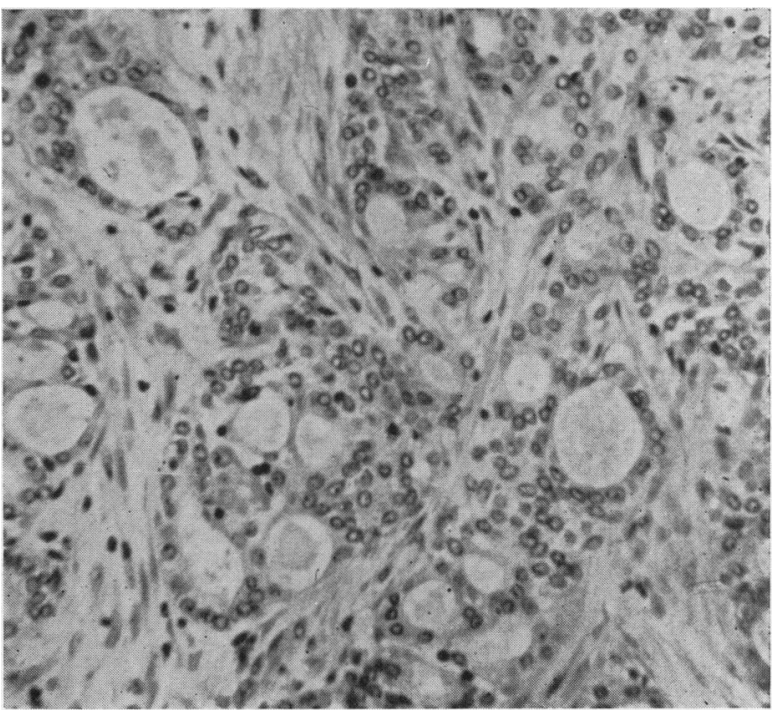

FIG. 3.-Photomicrograph of a section cut from the adenoma showing vesicles. $\times 150$. 
may be shown as an area of obstructive emphysema on comparing radiographs taken in full inspiration and expiration. On bronchography there is a filling defect in the bronchus involved, the lipiodol ending abruptly at the obstruction, in contradistinction to the 'rat-tail' constriction seen in a carcinoma.

The treatment of bronchial adenoma depends on the degree of extrabronchial extension that exists, and also on the effect of the tumour on the segment or lobe distal to it. Small tumours may be treated by bronchoscopic removal, but larger ones are best removed by transpleural bronchotomy, if necessary with excision of the wall and bronchial reconstruction (d'Abreu and MacHale, 1952; Price Thomas, 1954). Should complications, such as bronchiectasis or lung abscess, have occurred distal to the tumour, the required treatment is resection of the affected part of the lung, together with the tumour (d'Abreu, 1953).

I am greatly indebted to Mr. A. L. d'Abreu for permission to publish this report and for advice in the preparation of this paper. I must also thank Dr. H. S. Baar for the histological report, and Mr. G. Williamson for the photomicrographs and the radiograph.

\section{REFERENCES}

Berger, S. M., Boreadis, A. G. and Kremens, V. (1953). J. Pediat., 43, 417. .
d'Abreu, A. L.
London. London.

Foster-Carter, A. F. (1941). Quart. J. Med., n.s. 10, 139.

Jesberg, S. (1926). Ann. Otol., St. Louis, 35, 905.

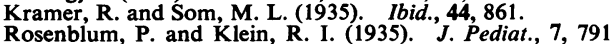

Thomas, C. Price (1954). Lancet, 1, 1 . 